\title{
CONSUMO DE ÁGUA EM PLANTIOS DE EUCALIPTO: PARTE 1 DETERMINAÇÃO DA CONDUTÂNCIA ESTOMÁTICA EM TRATAMENTOS IRRIGADO E NÃO-IRRIGADO ${ }^{1}$
}

\author{
Rogério Lessa de Castro Carneiro², Aristides Ribeiro ${ }^{3}$, Carlos Alberto Martinez y Huaman ${ }^{4}$, Fernando \\ Palha Leite ${ }^{5}$, Gilberto Chohaku Sediyama ${ }^{3}$ e Nairam Felix de Bastos ${ }^{6}$
}

\begin{abstract}
RESUMO - Devido ao grande interesse sobre a necessidade hídrica em cultivos de eucalipto e qual a resposta da planta às condições ambientais, esta pesquisa teve como objetivo calcular o consumo de água em plantios de eucalipto com 2 anos de idade. O trabalho foi composto por duas partes, sendo a primeira dedicada à determinação da condutância estomática em clones de Eucalyptus grandis x Eucalyptus urophylla irrigados e não-irrigados e à verificação do efeito da variação sazonal das varáveis ambientais. A segunda parte compreendeu a modelagem da resistência estomática e o cálculo da transpiração pelo método de Penman-Monteith. O sítio experimental localizava-se no Município de Belo Oriente, Estado de Minas Gerais, a 19¹8'23” S de latitude, 42²2'46” W de longitude e $220 \mathrm{~m}$ de altitude. Na primeira parte, a condutância estomática foi medida em três períodos diferentes: período úmido, início do período seco e período seco. Valores médios da condutância estomática variando entre 0,41 e $0,22 \mathrm{~mol} \mathrm{~m}^{-2} \mathrm{~s}^{-1}$ no plantio irrigado e entre 0,38 e $0,24 \mathrm{~mol} \mathrm{~m}^{-2} \mathrm{~s}^{-1}$ no não-irrigado foram encontrados. Também, verificou-se que a condutância estomática sofreu variação entre os períodos úmido e seco, a qual foi relacionada com algumas variáveis ambientais e umidade do solo.
\end{abstract}

Palavras-chave: Condutância estomática, necessidade hídrica e variação sazonal de eucalipto.

\section{WATER CONSUMPTION IN EUCALYPT PLANTATION: PART 1 DETERMINATION OF STOMATAL CONDUCTANCE IN IRRIGATED AND NON-IRRIGATED TREATMENTS}

\begin{abstract}
In response to the growing interest in hydric need in eucalypt plantations and plant response as a function of environmental conditions, this work aimed to calculate water consumption in 2-year-old Eucalyptus grandis $x$ Eucalyptus urophylla clones located both on irrigated and non-irrigated plantations. This work is divided into two parts. In the first, stomatal conductance is determined and the effect of seasonal variability of environmental variables is verified. In the second, stomatal resistance is modeled and eucalypt transpiration is calculated by the Penman-Monteith method. The experimental site was located in Belo Oriente, Minas Gerais, at 19¹8'23" S latitude, 42 $22^{\prime} 46^{\prime \prime}$ W longitude and 220 m altitude. Stomatal conductance was measured in three different periods: humid period, early dry period, and dry period. Average values
\end{abstract}

\footnotetext{
${ }^{1}$ Recebido em 19.05.2006 e aceito para publicação em 15.12.2007.

${ }^{2}$ Instituto Nacional de Pesquisas Espaciais Cptec/Inpe. E-mail : <carneiro@cptec.inpe.br>.

${ }^{3}$ Departamentod e Engenharia Agrícola da Universidade Federal de Viçosa (UFV). E-mail: <ribeiro@ufv.br>e < sediyama@ufv.br> .

${ }^{4}$ Faculdade de Filosofia, Ciências e Letras de Ribeirão Preto,USP. E-mail: <carlosamh@ffclrp.usp.br>.

${ }^{5}$ Celulose-Nipo-Brasileira, CENIBRA. E-mail: < fernando.leite@cenibra.com.br>.

${ }^{6}$ Departamento de Solos da UFV. E-mail :<nfbarros@ufv.br $>$
} 
of stomatal conductance ranged from 0.41 to $0.22 \mathrm{~mol} \mathrm{~m}^{-2} \mathrm{~s}^{-1}$ for the irrigated treatment and from 0.38 to $0.24 \mathrm{~mol} \mathrm{~m}^{-2} \mathrm{~s}^{-1}$ for the non-irrigated treatment. Stomatal conductance was also found to decrease between the humid and dry periods. This variation was related with some environmental variables and soil moisture.

Keywords: Stomatal conductance, hydric needs, seasonal variation and eucalypt.

\section{INTRODUÇÃO}

O ciclo hidrológico em ambientes florestais depende da precipitação, interceptação da água pelo dossel, do escoamento lateral, da drenagem profunda e transpiração (ALMEIDAe SOARES, 2003). A crescente pressão por uma política florestal, ambientalmente sustentável, requer melhor entendimento quanto à fisiologia do crescimento e as relações hídricas das espécies florestais (LIMA, 1996).

Vários fatores controlam as interações entre o sistema solo-planta-atmosfera em plantios de eucalipto, dentre os quais se destacam os fatores fisiológicos e as condições ambientais. As principais variáveis ambientais que controlam as trocas gasosas entre o dossel vegetal e a atmosfera são: irradiância solar, disponibilizando energia para o processo de evaporação e transpiração; temperatura do ar, controlando o déficit de pressão de vapor entre a cavidade estomatal e a atmosfera; disponibilidade de água no solo, e que regula a abertura estomática e conseqüentemente, o processo de difusão do vapor de água entre a cavidade estomatal e a atmosfera, podendo afetar a produtividade, como verificado por Souza (2006). Muitos estudos foram realizados no sentido de quantificar a magnitude dos efeitos climáticos sobre o controle estomático nas trocas gasosas e na produtividade, destacando-se os realizados por Hall et al. (1976), Sheriff (1979), Jarvis e McNaughton, (1986) Landsberg e Butller (1980), Ludlow (1980), Jarvis (1980), Whitehead et al. (1981), Schulze et al. (1987), Tenhunen et al. (1987), Mielke et al. (1999), Gao (2000), Soares e Almeida (2001) e Thomas et al. (2006). O objetivo deste estudo foram quantificar a condutância estomática e verificar os efeitos da variação sazonal das variáveis ambientais em plantios de eucalipto irrigados e nãoirrigados.

\section{MATERIAL E MÉTODOS}

O sítio experimental localizava-se no Município de Belo Oriente, MG, situado a $19^{0} 18^{\prime} 23^{\prime \prime}$ S de latitude, $42^{\circ} 22^{\prime} 46^{\prime \prime} \mathrm{W}$ de longitude e $220 \mathrm{~m}$ de altitude. A região possui clima do tipo Aw, segundo a classificação de Köppen, temperado chuvoso-mesotérmico, com precipitação média anual de $1.163 \mathrm{~mm}$, temperatura média anual de $25,2{ }^{\circ} \mathrm{C}$, média das temperaturas máximas de $31,5^{\circ} \mathrm{C}$, médias das temperaturas mínimas de $19,1^{\circ} \mathrm{C}$ e umidade relativa média de 65,2\%.

O estudo foi conduzido em povoamentos clonais de híbridos de Eucalyptus grandis x Eucalyptus urophylla, com 14 meses após o plantio, plantados em 17/10/2001, em espaçamento 3 x $3 \mathrm{~m}$. O solo predominante da área experimental é classificado como Neossolo Flúvico. O experimento foi composto por duas parcelas, sendo uma irrigada com $1.956 \mathrm{~m}^{2}$ (55,50 x 35,25 m) e outra não-irrigada com 2.545 m² $^{2}$ (130,50 x 19,5 m). Empregou-se um sistema de irrigação por gotejamento, permitindo que no período de coletas de dados o tratamento irrigado não sofresse deficiência hídrica. Ambos os tratamentos receberam adubação e tratamento fitossanitário e não sofreram desrama em nenhuma fase de desenvolvimento. Foram realizadas coletas de dados (referidos adiante, campanhas) em três períodos distintos (Quadro 1), na intenção de caracterizar diferentes períodos em relação à disponibilidade de água no solo e condições ambientais. Permite-se, assim, determinar a magnitude desses fatores no processo de trocas gasosas entre o dossel vegetal e a atmosfera, em diferentes períodos sazonais.

Para obter a condutância estomática do vapor de água nas duas primeiras campanhas, utilizou-se um porômetro de difusão AP4 (Delta T, Cambridge, England); na terceira, um Analisador de Gás Infravermelho (IRGA) LC-PRO (ADC, Hoddesdon, UK). A utilização do IRGA na terceira campanha se deve à aquisição após o início do experimento. A justificativa da utilização se atribui ao fato de o aparelho possuir mais recursos operacionais e menores restrições às condições de operação que o utilizado nas duas primeiras campanhas. Testes mostraram que as medidas realizadas pelos aparelhos não diferenciaram entre si. 
Consumo de água em plantios de eucalipto: parte 1 ...

Quadro 1 - Cronograma de execução das três campanhas (C1, C2 e C3) de coleta de dados nos tratamentos irrigado (IR) e não-irrigado (NI)

Table 1 - Chronogram of the three series (C1, C2 and C3) for data collection in the irrigated (IR) and non-irrigated treatments (NI)

\begin{tabular}{|c|c|c|c|c|c|}
\hline Campanha & Tratamento & Início & Final & № de Dias & Período \\
\hline $\mathrm{C} 1$ & IR & $12 / 03 / 2003$ & $28 / 03 / 2003$ & 13 & Úmido \\
\hline C1 & NI & $07 / 04 / 2003$ & $16 / 04 / 2003$ & 8 & Úmido \\
\hline $\mathrm{C} 2$ & IR & $31 / 07 / 2003$ & $08 / 08 / 2003$ & 7 & Início do seco \\
\hline C2 & NI & $22 / 07 / 2003$ & $30 / 07 / 2003$ & 7 & Início do seco \\
\hline C3 & IR & $17 / 09 / 2003$ & $19 / 09 / 2003$ & 3 & Seco \\
\hline C4 & NI & $23 / 09 / 2003$ & $25 / 09 / 2003$ & 3 & Seco \\
\hline
\end{tabular}

A condutância estomática e as variáveis ambientais foram coletadas com o auxílio de uma torre de medidas micrometeorológicas com 25 m de altura, localizadas exatamente entre quatro árvores localizada no centro de cada tratamento. Isso possibilitou amostrar um quadrante de cada árvore por vez, simulando os quatros diferentes na exposição da copa da árvore em relação à posição do sol (Figura 1a).

Nas campanhas realizadas com o porômetro, a copa de cada árvore ao redor da torre micrometeorológica foi dividida em duas partes, uma superior e outra inferior (Figura 1b). Por recomendações operacionais, o aparelho operou somente quando a umidade relativa estivesse abaixo de $80 \%$. Assim, as leituras foram iniciadas no início da manhã, quando a umidade relativa atingia valores menores que $80 \%$ e finalizadas à tarde, quando a umidade relativa alcançava esse limiar. Inicialmente, as leituras foram realizadas na camada inferior, amostrando aleatoriamente uma folha de cada quadrante de uma das quatro árvores por vez e evitando folhas danificadas devido à ação mecânica ou ação de agentes patogênicos. Terminadas as quatro leituras (uma em cada árvore), esse procedimento foi realizado na parte superior da copa. O procedimento foi repetido por mais duas vezes. Todo esse procedimento foi realizado a cada $30 \mathrm{~min}$ até que a umidade relativa alcançasse $80 \%$.

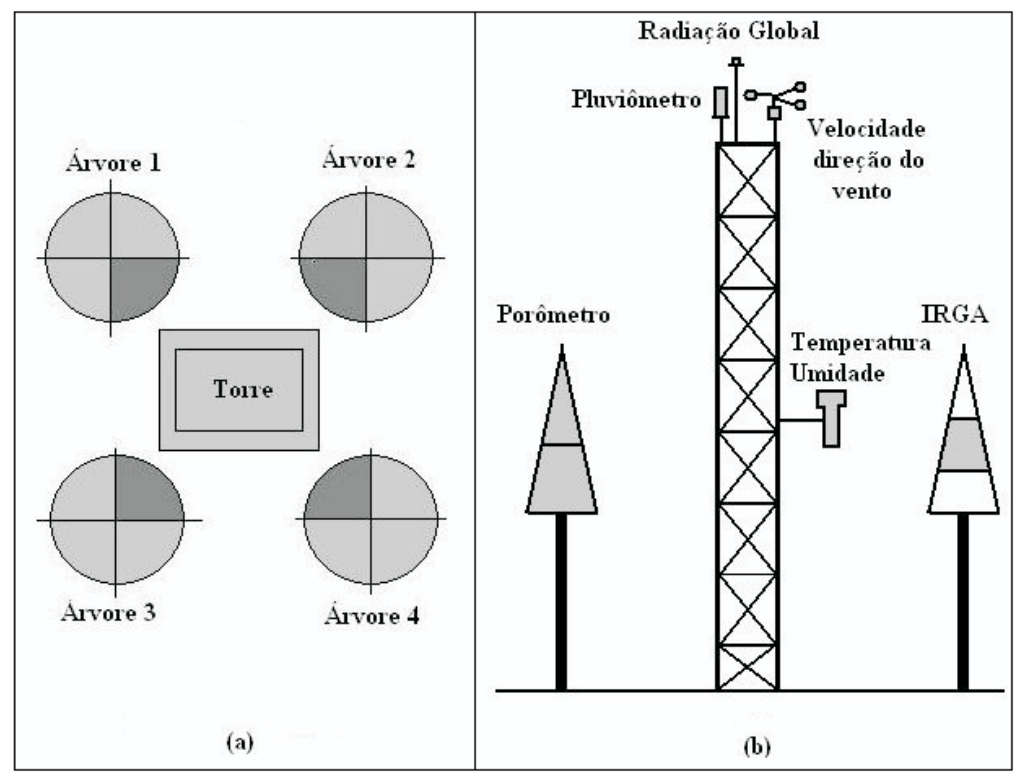

Figura 1 - Vista superior do desenho experimental, localização da torre micrometeorológica entre as árvores e quadrantes amostrados de cada copa de árvore (a), posicionamento dos sensores e esquema de divisão da copa das árvores para medidas da condutância estomática.

Figure 1 - Upper view of the experimental design, micrometeorological tower position among the trees and sampled quadrants of each treetop (a), sensor positioning and treetop division scheme for measuring stomatal conductance. 
Em razão de o IRGA não apresentar restrições quanto à umidade relativa, as leituras iniciavam-se às 8h30 e cessavam às $17 \mathrm{~h}$. Porém, o tempo de resposta do aparelho é menor que o do porômetro. Dessa maneira, as leituras concentraram-se na porção média da copa (Figura 1b), e esse procedimento foi repetido a cada $90 \mathrm{~min}$. Essas leituras foram realizadas amostrandose uma folha de cada árvore ao redor da torre micrometeorológica por vez e tendo os mesmos cuidados descritos na utilização do porômetro. Quando terminadas as quatro leituras (uma em cada árvore), o procedimento foi repetido por mais quatro vezes.

Para diagnosticar as variáveis ambientais, diferentes sensores foram instalados nas torres experimentais (Quadro 2). Dados de temperatura e umidade relativa do ar foram coletados em nível médio da copa das árvores. No topo da torre foram instalados os seguintes sensores: piranômetro para medir a irradiância solar global; pluviômetro para medir a intensidade e volume de precipitação; e anemômetro de copo para velocidade e direção do vento (Figura 1b). Os dados foram coletados em intervalos de $1 \mathrm{seg}$, sendo as médias armazenadas ininterruptamente a cada $10 \mathrm{~min}$, em um datalogger. Com os valores de umidade relativa e temperatura, calculou-se o valor do déficit de pressão de vapor. Os dados de umidade do solo foram coletados às profundidades de 30, 60, 90, 120, 150, 180 e $210 \mathrm{~cm}$, com uma sonda de nêutrons (Quadro 2). Também, monitorou-se, durante todo o experimento, o nível do lençol freático com o auxílio de quatro piezômetros instalados em cada tratamento. As variáveis ambientais analisadas foram irradiância solar global, temperatura, déficit de pressão de vapor, velocidade do vento, precipitação e umidade do solo. Todos os valores aqui apresentados se referem aos períodos em que foram realizadas as campanhas de medidas de condutância estomática.

A irrigação na primeira campanha não foi necessária devido ao bom volume de água precipitado (Figura 2). Durante a segunda campanha foram realizadas três irrigações, sendo uma anterior ao início da campanha (4,2 mm) em 22/07/2003, outra (5,8 mm) em 28/07/2003 e a última (3,4 mm) em 04/08/2003, conforme se observa na Figura 3. Na terceira campanha, realizou-se uma irrigação de 5,0 mm antes do início da campanha em 17/09/2003 e outra de 5,4 mm durante a campanha em 23/09/2003, e não ocorreu nenhuma precipitação pluviométrica.

Quadro 2 - Especificações dos sensores utilizados para medição das variáveis ambientais Table 2 -Specifications of the sensors used for measuring the environmental variables

Sensor

Temperatura e umidade

Piranômetro

Pluviômetro

Anemômetro

Datalogger

Umidade do solo
Especificação

HMP45C (Vaisala, Helsinski, Finland)

CM-3 (Kipp Zonen, Röntgenweg, The Netherlands)

CS700-L(Campbell Scientific Instruments, Utah, USA)

03101-5 (Campbell Scientific Instruments, Utah, USA)

CR10X (Campbell Scientific Instruments, Utah, USA)

503DR (CPN International, Martinez, Califórnia, USA)

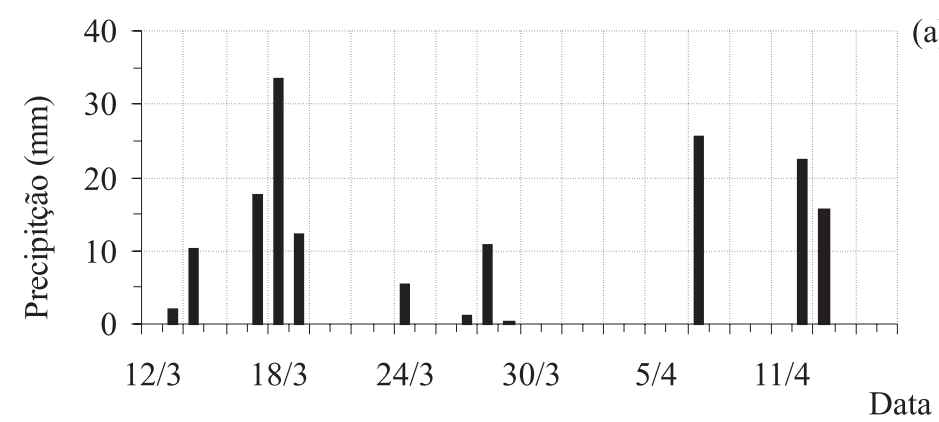

(a)

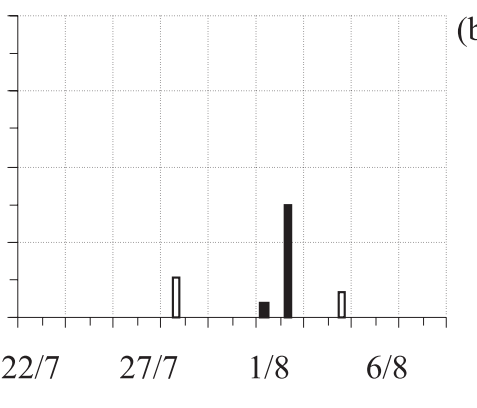

(b)

Data

Figura 2 - Totais diários de precipitação (barras pretas) e total diário de irrigação (barras brancas) verificados durante a primeira campanha intensiva (a) e a segunda campanha intensiva (b).

Figure 2 - Total daily rainfall (black bars) and total daily irrigation (white bars) verified at the first intensive series (a) and second intensive series (b).

R. Árvore, Viçosa-MG, v.32, n.1, p.1-10, 2008 


\section{RESULTADOS E DISCUSSÃO}

\subsection{Caracterização climática e variação na umidade do solo}

No Quadro 3, apresenta-se a média diária das variáveis ambientais em cada campanha. Verifica-se, nesse quadro, que durante as duas primeiras campanhas os dias no tratamento irrigado foram com menor nebulosidade, conseqüentemente maior radiação incidente em comparação com os dias no tratamento não-irrigado. Isso refletiu os valores de temperatura, déficit de pressão de vapor (DPV) e velocidade do vento devido à maior quantidade de energia disponível. Dessa maneira, os dias nas duas primeiras campanhas no tratamento irrigado foram dias mais favoráveis à maior taxa de transpiração.

Durante a terceira campanha, os dias no tratamento não-irrigado apresentaram menor nebulosidade, ao contrário do que ocorreu nas duas primeiras campanhas. Essa maior disponibilidade energética no tratamento não-irrigado também refletiu em maiores valores de temperatura, DPV e velocidade do vento (Quadro 3), devido à maior energia disponível pela maior radiação incidente.

Realizou-se a análise de variância para comparação das médias das variáveis ambientais entre os tratamentos na mesma campanha e entre os mesmos tratamentos em campanhas diferentes. Posteriormente, aplicou-se o teste de Tukey para verificar se as médias diferenciavam entre si. Os resultados do teste de Tukey são apresentados no Quadro 4.

Na primeira campanha, o total precipitado atingiu $110,8 \mathrm{~mm}$, e $85,4 \mathrm{~mm}$ desse total ocorreram durante a coleta no tratamento irrigado e $25,4 \mathrm{~mm}$ no tratamento não-irrigado (Figura 2).
Quadro 4-Resultado do teste de Tukey comparando as médias das variáveis ambientais entre tratamentos nas mesmas campanhas e entre os mesmos tratamentos em diferentes campanhas: primeira campanha irrigado (C1_IR), primeira campanha não-irrigado (C1_NI), segunda campanha irrigado (C2_IR), segunda campanha não-irrigado (C2_NI), terceira campanha irrigado (C3_IR) e terceira campanha não-irrigado (C3_NI)

Table 4 - Tukey test results comparing the environmental variables of the treatments in the same series and among the same treatments in the different series, first irrigated series (C1_IR), first non-irrigated series $\left(C 1 \_N I\right)$, second irrigated series (C2_IR), second non-irrigated series (C2_NI), third irrigated series (C3_IR) and third non-irrigated series (C3_NI)

\begin{tabular}{lllll}
\hline & $\mathrm{Rg}$ & $\mathrm{t}$ & $\mathrm{DPV}$ & $\mathrm{vv}$ \\
\hline Entre Tratamentos & & & & \\
C1_IR x C1_NI & $\mathrm{ns}$ & $\mathrm{ns}$ & $\mathrm{ns}$ & $\mathrm{ns}$ \\
C2_IR x C2_NI & $\mathrm{ns}$ & $\mathrm{ns}$ & $\mathrm{ns}$ & $\mathrm{ns}$ \\
C3_IR x C3_NI & $* *$ & $\mathrm{~ns}$ & $* *$ & $* *$ \\
Entre Campanhas & & & & \\
C1_ IR x C2_IR & $\mathrm{ns}$ & $* *$ & $\mathrm{~ns}$ & $\mathrm{~ns}$ \\
C1_IR x C3_IR & $* *$ & $* *$ & $\mathrm{~ns}$ & $\mathrm{~ns}$ \\
C2_IR x C3_IR & $* *$ & $\mathrm{~ns}$ & $\mathrm{~ns}$ & $\mathrm{~ns}$ \\
C1_ NI x C2_NI & $\mathrm{ns}$ & $* *$ & $\mathrm{~ns}$ & $\mathrm{~ns}$ \\
C1_NI x C3_NI & $\mathrm{ns}$ & $* *$ & $* *$ & $* *$ \\
C2_ NI x C3_NI & $\mathrm{ns}$ & $* *$ & $* *$ & $\mathrm{~ns}$ \\
\hline
\end{tabular}

Ns: não-significativo e ** significativo a $1 \%$ de probabilidade.

Durante a segunda campanha foram totalizados 17,0 mm de precipitação. Desse total, 2,0 mm durante a coleta de dados no tratamento irrigado e $15,0 \mathrm{~mm}$ antes de iniciar a coleta no tratamento não-irrigado, conforme observado na Figura 3. Embora tenha sido verificado reduzido total de precipitação durante a segunda campanha, nos dias em que antecederam esse período ocorreram chuvas, garantindo a umidade do solo.

Na terceira campanha não ocorreram precipitações antes e durante, sendo relativas ao período seco do ano.

Quadro 3 - Médias das médias das variáveis meteorológicas dos tratamentos irrigado (IR) e não-irrigado (NI), nas três campanhas (C1, C2 e C3)

Table 3 - Meteorological variable averages for the irrigated (IR) and non-irrigated (NI) treatments for the three series (C1, C2 and C3)

\begin{tabular}{|c|c|c|c|c|c|c|}
\hline \multirow[t]{2}{*}{ Variável Meteorológica } & \multicolumn{2}{|c|}{$\mathrm{C} 1$} & \multicolumn{2}{|c|}{$\mathrm{C} 2$} & \multicolumn{2}{|c|}{$\mathrm{C} 3$} \\
\hline & IR & NI & IR & NI & IR & NI \\
\hline Irradiância Solar Global ( $\left.\mathrm{MJ} \mathrm{m}^{-2} \mathrm{~d}^{-1}\right)$ & 17,9 & 14,5 & 16,6 & 14,5 & 9,0 & 20,3 \\
\hline Temperatura do ar $\left({ }^{\circ} \mathrm{C}\right)$ & 25,3 & 24,5 & 21,1 & 20,1 & 21,8 & 22,2 \\
\hline Déficit de pressão de vapor (kPa) & 0,73 & 0,57 & 0,78 & 0,71 & 0,56 & 1,14 \\
\hline Velocidade do vento ( $\left.\mathrm{m} \mathrm{s}^{-1}\right)$ & 0,19 & 0,12 & 0,25 & 0,20 & 0,14 & 0,32 \\
\hline
\end{tabular}


A umidade média do solo foi sempre maior no tratamento irrigado, variando ligeiramente ao longo do experimento. Também, verificou-se redução na umidade média do solo na transição entre os períodos úmido e seco (Figura 3a).

Na Figura 3b, observa-se o efeito da irrigação no perfil de umidade do solo, em que a maior umidade se concentra nas proximidades da superfície entre 60 e $90 \mathrm{~cm}$ de profundidade, devido à aplicação de água pelo sistema de gotejamento. Em profundidades maiores que $90 \mathrm{~cm}$, a umidade é reduzida progressivamente até atingir $240 \mathrm{~cm}$, quando novamente começa a aumentar devido à contribuição de água pelo lençol freático.
A pequena umidade observada na camada de até 30 $\mathrm{cm}$, em comparação com aquelas entre 60 e $90 \mathrm{~cm}$, pode ser explicada em razão da maior concentração de raízes finas nessa camada, as quais são mais eficientes na extração de água do solo, conforme verificado por Sacramento Neto (2001).

Na Figura 3c, apresenta-se o perfil da umidade do solo no tratamento não-irrigado, em que a umidade é maior nas camadas mais próximas na superfície do solo, reduzindo com o aumento da profundidade em maior taxa que no tratamento irrigado e tornando a aumentar nas profundidades maiores que $240 \mathrm{~cm}$, devido à contribuição do lençol freático.
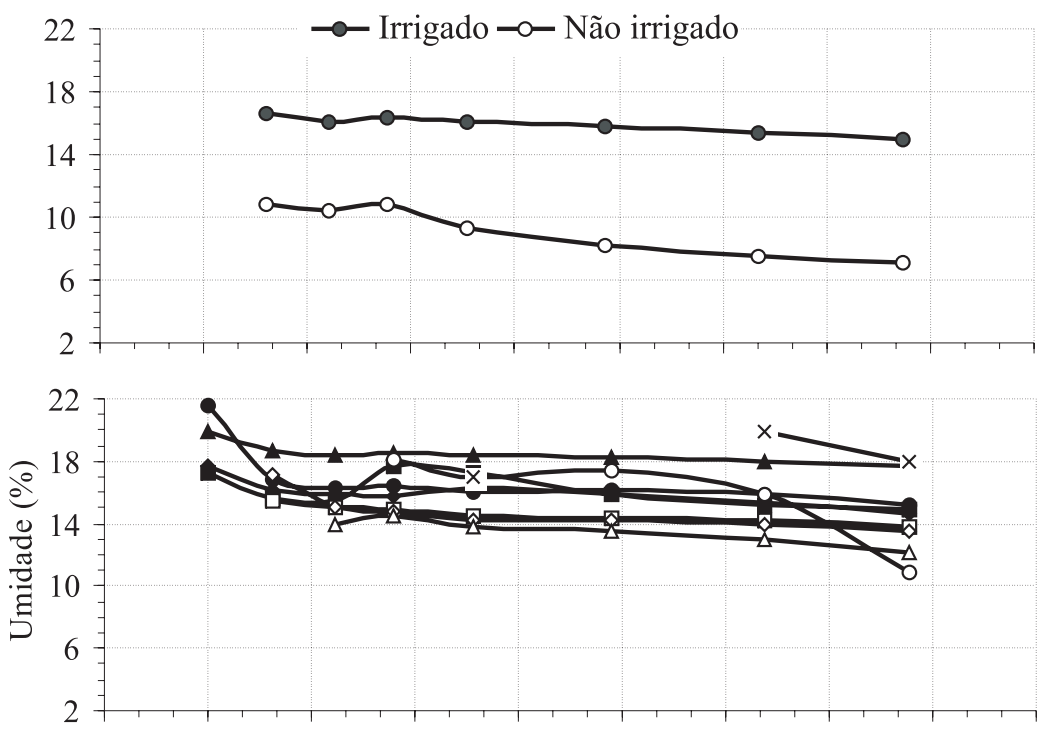

(b)

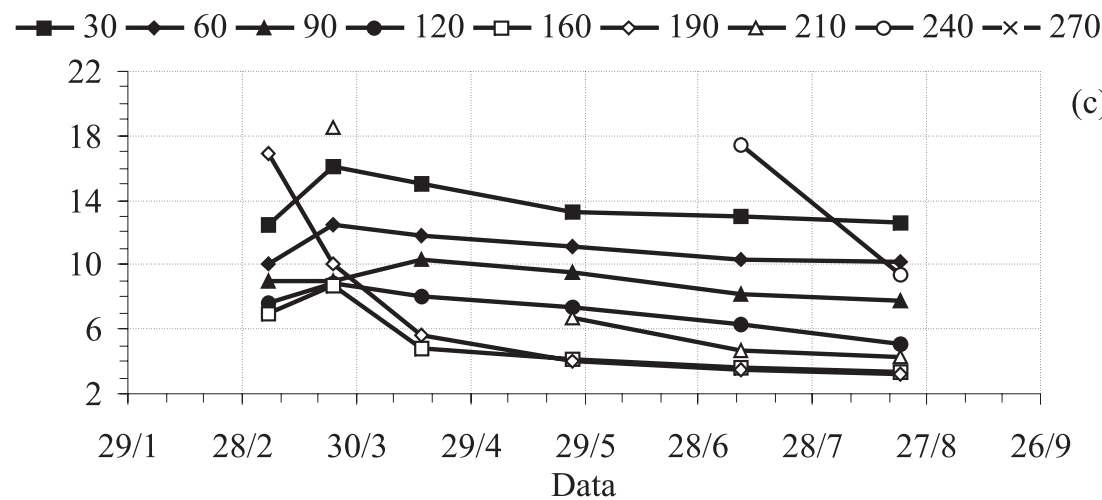

Figura 3 - Média da umidade do solo no perfil do solo (a), perfil de umidade do solo em base gravimétrica do tratamento irrigado (b) e perfil de umidade do solo em base gravimétrica do tratamento não-irrigado (c).

Figure 3 - Soil moisture average in the soil profile (a), soil moisture profile in gravimetric basis for the irrigated treatment (b) and soil moisture profile in gravimetric basis for the non-irrigated treatment (c).

R. Árvore, Viçosa-MG, v.32, n.1, p.1-10, 2008 
O experimento foi conduzido em uma área de baixada, próximo ao leito de um riacho, onde o nível do lençol freático se apresentou próximo à superfície, mesmo durante o período seco do ano (Figura 4). As altas umidades nas camadas inferiores, verificadas nos dois tratamentos (Figura 3bc), podem ser explicadas em razão da contribuição do lençol freático (Figura 4).

\subsection{Condutância estomática}

De acordo com o Quadro 6, verificou-se que a condutância estomática média não diferiu entre os tratamentos. Observam-se nesse quadro, maiores valores da condutância estomática no tratamento irrigado do que no não-irrigado, à exceção da terceira campanha (Figura 5). Observou-se também uma redução na condutância estomática, com a aproximação do período seco.

Entre a primeira e segunda campanhas não foi possível inferir se a diferença entre os tratamentos irrigados e não-irrigados foi ocasionada pelas condições ambientais. No Quadro 4, pode-se verificar que os valores das variáveis ambientais mostrados no Quadro 3, apesar de maiores no tratamento irrigado, não diferem entre si. Isso indica que o experimento foi conduzido nas mesmas condições ambientais. Entretanto, a disponibilidade hídrica no tratamento irrigado foi sempre maior que no tratamento não-irrigado, nas três campanhas, mesmo com a ocorrência de chuvas antes das campanhas (Figura 2). Logo, os maiores valores da condutância estomática no tratamento irrigado podem ser explicados pela maior disponibilidade hídrica verificada no tratamento irrigado (Figuras 3 e 4). Na Figura 3a, mostrase que, em média, a umidade do solo foi sempre maior no tratamento irrigado, enquanto na Figura 4 o nível do lençol freático está mais próximo da superfície no tratamento irrigado, aumentando a contribuição de água nos níveis mais profundos.

Nas duas primeiras campanhas no tratamento irrigado, a condutância estomática atingiu valores máximos logo no início da manhã. No tratamento nãoirrigado, os valores máximos da condutância estomática foram próximos às $12 \mathrm{~h}$ do horário local. Tal fato também pode ser explicado pela maior umidade do solo. $\mathrm{Na}$ Figura 3bc, mostram-se que a umidade do solo, além de maior, é distribuída mais uniformemente no perfil do solo no tratamento irrigado que no não-irrigado. Durante o período noturno na ausência de transpiração, a água é redistribuída no perfil do solo, como observado por Oliveira et al. (2005). Após essa redistribuição da água no perfil do solo no tratamento irrigado, em que a umidade é maior, a tensão pela qual a água está aderida às partículas de solo é menor que no tratamento nãoirrigado. Dessa forma, é necessário menos quantidade de energia para o processo de transpiração, ou seja, menor quantidade de energia solar, menor déficit de pressão de vapor e menores temperaturas são necessários para que o processo de transpiração seja intensificado. Assim, no início da manhã pouca energia é capaz de ativar os estômatos para que a condutância estomática seja máxima no tratamento irrigado. Porém, no tratamento não-irrigado a condutância estomática máxima ocorreu próximo ao meio-dia, devido à necessidade de maiores quantidades de radiação solar, maior déficit de pressão de vapor e temperatura para retirada de água do solo e, conseqüentemente, atingir valores máximos de condutância estomática.

Na terceira campanha, o tratamento não-irrigado apresentou maiores valores de condutância estomática do que o tratamento irrigado. Nesse caso, a disponibilidade hídrica não foi o fator predominante no processo de transpiração e sim as condições ambientais. Nos Quadros 3 e 4, mostra-se que as condições de radiação, déficit de pressão de vapor e temperatura foram significativamente maiores no tratamento não-irrigado do que no irrigado, favorecendo a maior condutância estomática.

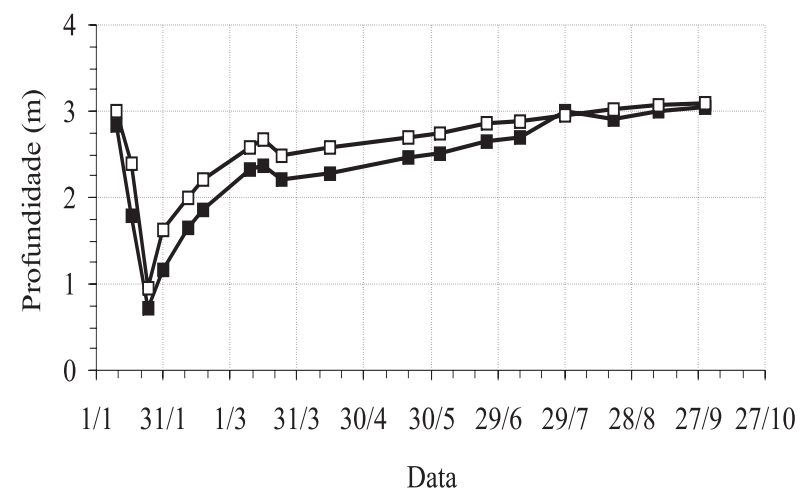

Figura 4-Profundidade do nível do lençol freático do tratamento irrigado indicado pelo quadrado preto e tratamento não-irrigado indicado pelo quadrado branco.

Figure 4 - Water table level depth for the irrigated treatment indicated by the black square and non-irrigated treatment indicated by the white square.

R. Árvore, Viçosa-MG, v.32, n.1, p.1-10, 2008 


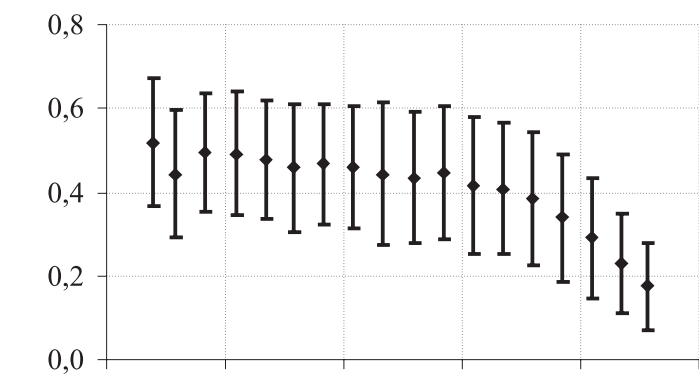

(a)
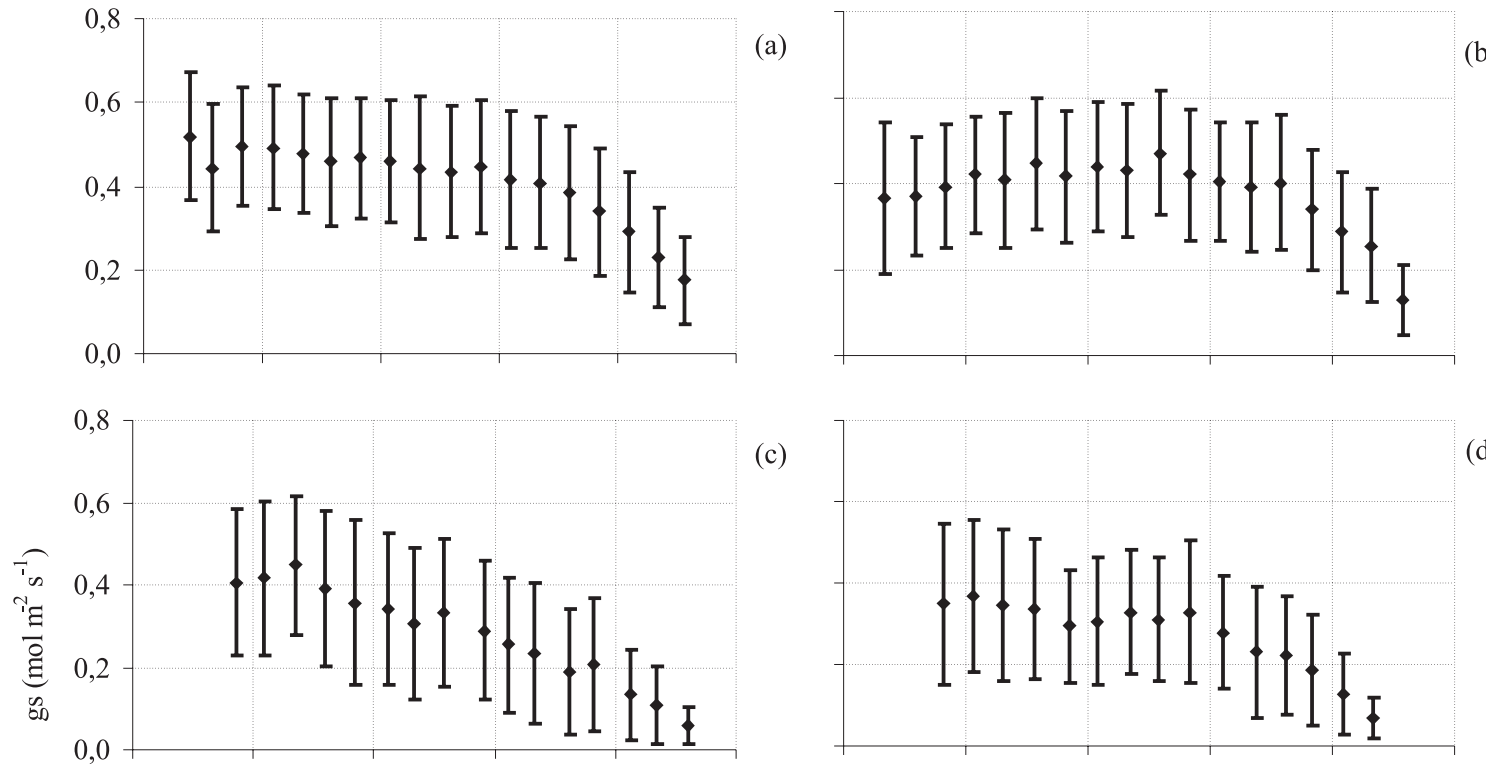

(c)

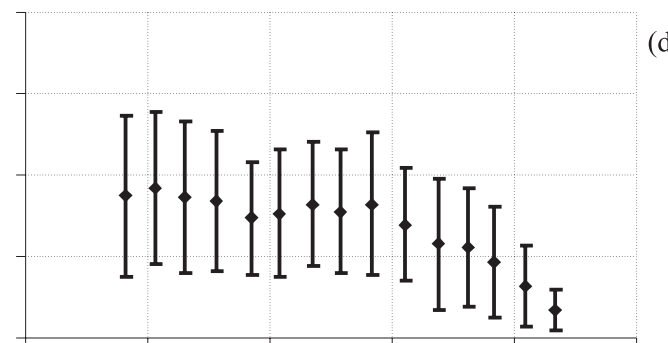

(d)
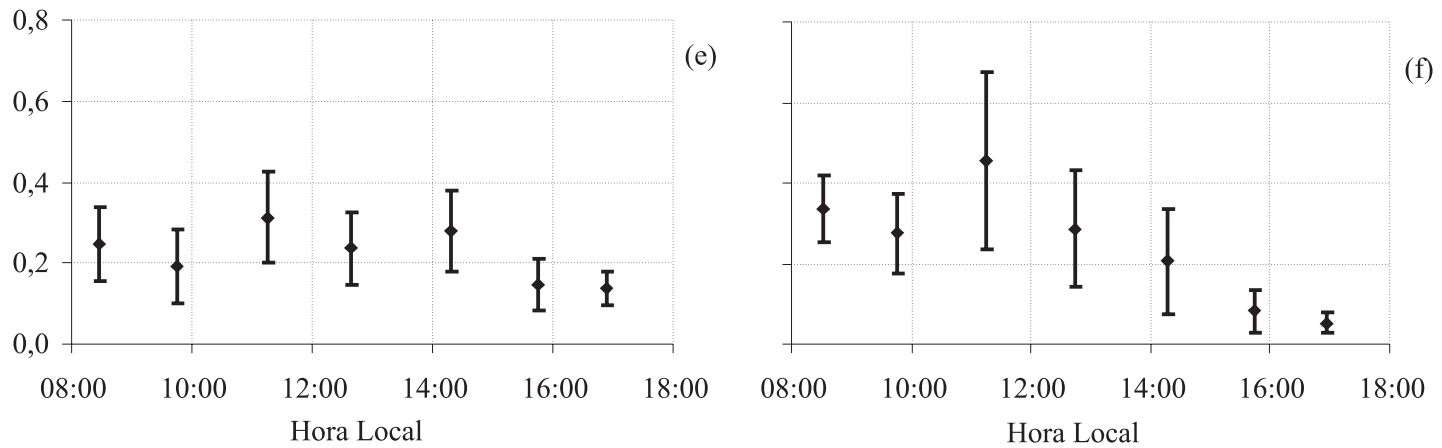

Figura 5 - Médias e desvios-padrão da variação diária da condutância estomática da primeira, segunda e terceira campanhas nos períodos úmidos (a), início do período seco (c) e período seco (e) no tratamento irrigado e períodos úmidos (b), início do período seco (d) e período seco (f) no tratamento não-irrigado.

Figure 5 - Averages and standard deviation of stomatal conductance daily variation for the first, second and third series in the humid period (a), early dry period (c) and dry period (e) in the irrigated treatment and humid period $(b)$, early dry period (d) and dry period $(f)$ in the non-irrigated treatment.

No Quadro 6, pode-se constatar que os tratamentos nas três campanhas não diferenciaram entre si. Ao comparar os mesmos tratamentos nas diferentes campanhas, verificou-se que não houve diferenças entre os mesmos tratamentos na segunda e terceira campanhas. Isso talvez possa ter ocorrido devido ao pequeno intervalo de tempo em que as campanhas foram realizadas, fazendo, assim, que a disponibilidade hídrica e a variação das condições ambientes não fossem suficientes para que as médias das condutâncias variassem significativamente.
Quadro 5 - Médias das condutâncias estomáticas (gs) dos tratamentos irrigado (IR) e não-irrigado (NI), nas três campanhas (C1, C2 e C3)

Table 5-Stomatal conductance averages (gs) for the irrigated (IR) and non-irrigated (NI) treatments for the three series (C1, C2 and C3)

\begin{tabular}{ccc}
\hline Campanha & Tratamento & (gs) $\left(\mathrm{mol} \mathrm{m}^{-2} \mathrm{~s}^{-1}\right)$ \\
\hline C1 & IR & 0.41 \\
C1 & NI & 0.38 \\
C2 & IR & 0.28 \\
C2 & NI & 0.27 \\
C3 & IR & 0.22 \\
C3 & NI & 0.24 \\
\hline
\end{tabular}


Quadro 6- Resultado do teste de Tukey comparando as médias das condutâncias estomáticas dos tratamentos e das campanhas, primeira campanha irrigado (C1_IR), primeira campanha não-irrigado (C1_NI), segunda campanha irrigado (C2_IR), segunda campanha não-irrigado (C2_NI), terceira campanha irrigado (C3_IR) e terceira campanha não-irrigado (C3_NI)

Table 6- Tukey test results comparing the stomatal conductance averages of both the treatments and series, first irrigated series (C1_IR), first non-irrigated series (C1_NI), second irrigated series (C2_IR), second non-irrigated series (C2_NI), third irrigated series (C3_IR) and third non-irrigated series (C3_NI)

\begin{tabular}{lc}
\hline & gs \\
\hline C1_IR x C1_NI & ns \\
C2_IR x C2_NI & ns \\
C3_IR x C3_NI & ns \\
C1_IR x C2_IR & $* *$ \\
C1_IR x C3_IR & $* *$ \\
C2_IR x C3_IR & $n s$ \\
C1_NI x C2_NI & $*$ \\
C1_N x C3_NI & $*$ \\
C2_NI x C3_NI & ns \\
\hline
\end{tabular}

ns: não significativo.

* significativo a $5 \%$ de probabilidade e ${ }^{* *}$ significativo a $1 \%$ de probabilidade.

Na Figura 5, observa-se que os valores de condutância estomática variaram entre 0,51 e $0,12 \mathrm{~mol}$ $\mathrm{s}^{-1} \mathrm{~m}^{-2}$ no período úmido, de 0,48 a $0,06 \mathrm{~mol} \mathrm{~s}^{-1} \mathrm{~m}^{-2}$ no início do período seco e de 0,36 a $0,05 \mathrm{~mol} \mathrm{~s}^{-1} \mathrm{~m}^{-2}$ na estação seca, aproximando-se daqueles encontrados por outros autores. Soares e Almeida (2001) e Almeida e Soares (2003) encontraram condutâncias estomáticas máximas em plantação de híbridos de E. grandis com 8 anos de idade, variando entre 0,15 e $0,50 \mathrm{~mol} \mathrm{~s}^{-1} \mathrm{~m}^{-}$ 2. Mielke et al. (1999) obtiveram valores médios diários variando entre 0,20 e $0,65 \mathrm{~mol} \mathrm{~s}^{-1} \mathrm{~m}^{-2}$, em plantação de híbridos de $E$. grandis, também com 8 anos de idade. Dye (1987) encontrou, na África do Sul, em um período de inverno seco, valores maiores variando entre 0,20 e $2,70 \mathrm{~mol} \mathrm{~s}^{-1} \mathrm{~m}^{-2}$, em quatro níveis do dossel vegetal para E. grandis com 5 anos de idade.

\section{CONCLUSÕES}

A condutância estomática de plantios jovens apresentou variação sazonal entre o período úmido e o inverno do período seco. Nos contrastes entre as médias das condutâncias estomáticas nas três campanhas realizadas em períodos diferentes, concluiu-se que, quando as condições ambientais foram iguais, a umidade do solo foi o fator predominante no controle da condutância estomática. Entretanto, pode-se perceber o papel essencial das condições ambientais no controle da condutância estomática, pois na terceira campanha mesmo o tratamento irrigado apresentando maior disponibilidade hídrica, a maior quantidade de energia recebida no tratamento não-irrigado foi o fator dominante no processo de transpiração.

\section{AGRADECIMENTOS}

À Coordenação de Aperfeiçoamento de Pessoal de Nível Superior (CAPES), pelo financiamento desta pesquisa; e à empresa florestal Celulose Nipo-Brasileira (CENIBRA), pelo fornecimento de apoios financeiro, logístico e de recursos humanos.

\section{REFERÊNCIAS}

ALMEIDA, A. C.; SOARES, J. V. Comparação entre o uso da água em plantações de eucalyptus grandis e floresta ombrófila densa (Mata Atlântica).

Revista Árvore, v.27, n.2, p.159-170, 2003.

DYE, P. J. Estimating water use by Eucalyptus grandis wich Penman-Monteith equation. In: VANCOUVER SYNPOSIUM - FOREST HIDROLOGY AND WATERSHED MANANEGENT, 1987, Vancouver. Preprints... Vancouver: International Association of hidrological Sciences, 1987. p.329-337.

GAO, F. Water relations and gas exchange of tropical sapling during a prolonged drought in a Bornean heath forest, with reference to root architecture. Journal of Tropical Ecology, v.16, p.101-116, 2000.

HALL. A. E.; SCHULZE, E. D.; CHIPPENDALE, G. $M$. Current perspectives of steady-state stomatal responses to environment. In: LANGE, O. L. et al. (Eds.). Water and plant life. Berlin: Springer-Verlag, 1976. p.169-188.

JARVIS, P. G. Stomatal response to water stress in Conifers. In: TURNER, P. J.; KRAMER, P. J. (Eds.) Adaptation of plants to water and righ temperature stress. New York: John-Wiley, 1980. p.105-122.

JARVIS, P. G.; McNAUGHTON, K. G. Stomatal control of transpiration: Scaling up from leaf to region. Advances in ecological research. New York: Academic Press, 1986.v.15. 49p.

R. Árvore, Viçosa-MG, v.32, n.1, p.1-10, 2008 
LANDSBERG, J. J.; BUTLER, D. R. Stomatal response to humidity: Implications for transpiration. Plant, Cells and Environment, v.3, p.29-33, 1980.

LIMA, W. P. Impactos ambientais do eucalipto. 2.ed. São Paulo: Universidade de São Paulo, 1996. 301p.

LUDLOW, M. M. Adaptative significanse of stomatal responses to water stress. In: WILSON, E. O. (Ed.) Adaptation of plants to water and righ temperature stress. New York: John-Wiley, 1980. p.123-138.

MIELKE, M. S. et al. Stomatal control of transpiration in the canopy of clonal Eucalyptus grandis plantation. Trees, v.13, n.1, p.152-160, 1999.

OLIVEIRA, R.S. et al. Hydraulic redistribuition in three Amazon trees. Oecology, v.145, p.354-363, 2005.

SACRAMENTO NETO, O. B. Balanço hídrico em plantios jovens de eucalipto na região de Belo Oriente-MG. 2001. $77 \mathrm{f}$. Dissertação (Mestrado em Meteorologia Agrícola) Universidade Federal de Viçosa, Viçosa, MG, 2001.

SCHULZE, E. D. et al. Stomatal responses to air humidity and to soil drought. In: ZEIGER, E. et al. (Eds.). Stomatal function. Stanford: Stanford University Press, 1987. p.311-321.
SHERIFF, D. W. Stomatal aperture the sensing of the environment by guards cells. Plant, Cells and Environment, v.2, n.1, p.15-22, 1979.

SOARES, J. V.; ALMEIDA, A. C. Modeling the water balance and soil water fluxes in a fast growing Eucalyptus plantation Brazil. Journal of Hidrology, v.253, n.1/4, p.130-147, 2001.

SOUZA, M. H. et al. Disponibilidade hídrica do solo e produtividade do eucalipto em três regiões da bacia do Rio Doce. Revista Árvore, v.30, n.3, p.399-410, 2006.

TENHUNEN, J. D.; PEARCY, R. W.; LANGE, O. L. Diurnal variation in leaf condutance and gas exchange in natural environments. In: ZEIGER, E. et al. (Eds.). Stomatal function. Stanford: Stanford University Press, 1987. p.323-351.

THOMAS, D. S.; MONTAGU, K. D.; CONROY, J. P. Effects of leaf and branch removal on carbon assimilation and stem wood density of Eucalyptus grandis seedlings. Trees, v.20, p 725-733, 2006.

WHITEHEAD, D.; OKALI, D. U. U.; FASEHUN, F. E. Stomatal response to environmental variables in two tropical species during the dry season in Nigeria. Journal of Applied Ecology, v.18, p.571-587, 1981. 